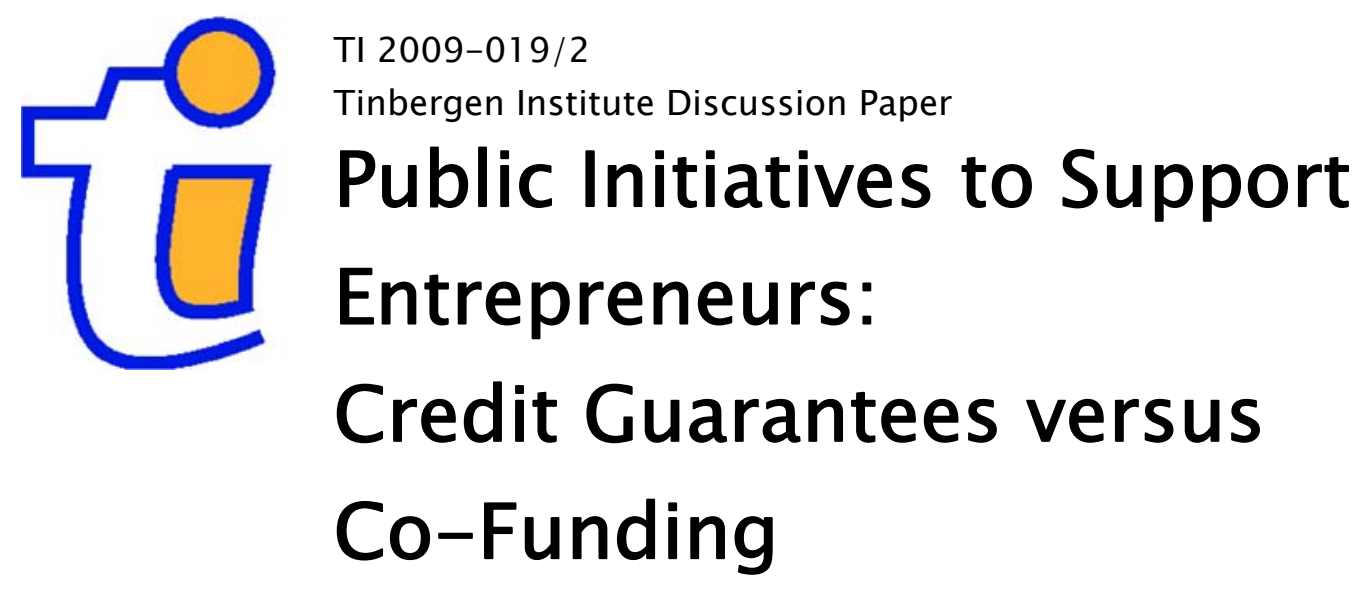

Stefan Arping ${ }^{\prime}$

Gyongyi Loranth²

Alan Morrison ${ }^{3}$

${ }^{1}$ Amsterdam Business School, University of Amsterdam, and Tinbergen Institute;

2 Judge Business School, University of Cambridge;

3 Said Business School, University of Oxford. 


\section{Tinbergen Institute}

The Tinbergen Institute is the institute for economic research of the Erasmus Universiteit Rotterdam, Universiteit van Amsterdam, and Vrije Universiteit Amsterdam.

Tinbergen Institute Amsterdam

Roetersstraat 31

1018 WB Amsterdam

The Netherlands

Tel.: +31(0)205513500

Fax: $+31(0) 205513555$

Tinbergen Institute Rotterdam

Burg. Oudlaan 50

3062 PA Rotterdam

The Netherlands

Tel.: + $31(0) 104088900$

Fax: $+31(0) 104089031$

Most TI discussion papers can be downloaded at http://www.tinbergen.nl. 


\title{
Public Initiatives to Support Entrepreneurs: Credit Guarantees versus Co-Funding*
}

\author{
Stefan Arping \\ University of Amsterdam
}

Gyöngyi Lóránth

University of Cambridge

\author{
Alan D. Morrison \\ University of Oxford
}

January 29, 2009

\footnotetext{
${ }^{*}$ We are grateful to Stijn Claessens, Quy-Toan Do, and participants at the World Bank Conference on Partial Credit Guarantees, March 13-14, 2008 for comments. Generous financial support from the World Bank is gratefully acknowledged.
} 


\title{
Public Initiatives to Support Entrepreneurs: \\ Credit Guarantees versus Co-Funding
}

\begin{abstract}
We analyze financial support for the entrepreneurial sector. State support can raise welfare by relaxing financial constraints, but it can also reduce lending standards if entrepreneurs substitute public sources of collateral for their own assets, if it encourages excessive entrepreneurial entry, or if it undermines bank monitoring incentives. We derive a "pecking order" for support schemes: support funds should be channeled first to credit guarantee schemes and then, when entrepreneurs start to substitute public for private collateral, to co-funding entrepreneurial projects. The optimal level of credit guarantee is diminishing in the costs of incentivising bank monitoring. We show in an extension that the long-term effect of public subsidies may be to impair the private sector's initiative to uncover cost savings.

Keywords: Partial Credit Guarantees, Co-funding and Loan Subsidies, Private Sector Initiative, Lending Standards
\end{abstract}

\section{Introduction}

Public credit guarantee programs are commonplace: Gudger (1998) and Beck, Klapper, and Mendoza (2008) document credit guarantee programs from both developing and developed countries all over the world. However, it is not clear a priori that guarantees necessarily increase welfare: for this to be the case, there must be a failure of private credit markets, and government involvement in credit markets must introduce fewer distortions than it resolves. In this paper, we examine conditions under which government intervention might raise welfare, and we discuss the optimal form of such intervention. Our analysis indicates that, even when there is a role for the State, a 


\section{PUBLIC INITIATIVES TO SUPPORT ENTREPRENEURS}

poorly designed support scheme need not increase welfare.

Public support initiatives for entrepreneurs are unnecessary when private markets function effectively. A pre-condition for welfare-increasing intervention is therefore that entrepreneurs with positive NPV investment opportunities be credit rationed. While the evidence on this point is mixed, a body of literature suggests that, in some circumstances, asymmetries of information between borrowers and lenders may restrict the flow of credit. ${ }^{1}$

Some evidence suggests that, if credit rationing is a problem, it can be ameliorated by credit guarantees. Zia (2008) examines the consequences for Pakistani exporters of cotton yarn of their 2001 withdrawal from the state-sponsored Export Finance Scheme. He finds that the consequence of this withdrawal was a significant reduction in exports by privately owned firms, while those of large publicly quoted exporters were unaffected. Zia argues that this indicates first that private firms were credit rationed, and second that the credit guarantee scheme reduced their rationing. Hancock, Peek, and Wilcox (2007) find evidence that loans guaranteed by the US Small Business Administration (SBA) between 1990 and 2000 were less affected by adverse economic shocks than non-guaranteed loans. Benavente, Galetovic, and Sanhueza (2006) study Chile's Fogape loan guarantee program, and present evidence that guarantees have increased access to credit for high-quality firms. Uesugi, Sakai, and Yamashiro (2006) discuss Japan's Special Credit Guarantee Program for Financial Stability, under which small and medium sized Japanese enterprises received government-sponsored credit guarantees between 1998 and 2001. Users of the program received more credit than non-users and experienced an increase in profitability. Wilcox and Yasuda (2008) provide evidence that government loan guarantees in Japan have increased the supply of nonguaranteed as well as guaranteed loans. And Banerjee and Duflo (2004) find that governmentsponsored direct lending programs in India tend to complement rather than substitute for other forms of credit. $^{2}$

\footnotetext{
${ }^{1}$ Important papers in this field are Fazzari, Hubbard, and Petersen (1988) and Hoshi, Kashyap, and Scharfstein (1990), presenting evidence that firms invest more when they have higher free cash flows, even after controlling for investment opportunities. Hubbard (1998) surveys the related literature.

${ }^{2}$ Other interesting empirical studies on credit guarantee schemes include Zecchini and Ventura (2006), who provide a difference-in-differences estimation approach to analyzing the effects of state-sponsored SME loan guarantees on loan volumes and interest rates in Italy, and Columba, Gambacorta, and Mistrulli (2008), who shed light on the economic effects of mutual loan guarantee consortia.
} 


\section{PUBLIC INITIATIVES TO SUPPORT ENTREPRENEURS}

Notwithstanding this evidence, credit guarantees need not necessarily enhance welfare. Even if they address a credit rationing problem, they may damage price signals, and so worsen borrower incentives. Lelarge, Sraer, and Thesmar (2008) present evidence from the French government loan guarantee program (Sofaris) that supports this concern. While they argue that the loan guarantees are effective in helping young French firms to find finance and to grow, they also find that guaranteed firms are more likely to adopt risky strategies, and that these firms file more often for bankruptcy.

A second question is, given that the state wishes to provide the entrepreneurial sector with subsidized funding, is a credit guarantee scheme the most effective way to do so? An alternative would be to offer a direct subsidy to entrepreneurs. This type of subsidy, which is sometimes referred to as a co-funding scheme, is also commonplace. For example, although there is a $\$ 100$ billion worldwide venture capital industry, the OECD (1997) reports that OECD governments invest about \$3 billion per year in small, innovative firms. Lerner (1999) documents massive levels of investment by government-sponsored credit agencies in the United States: in 1995, public venture capital initiatives invested $\$ 2.4$ billion in the United States, as against $\$ 3.9$ billion invested by private venture funds. Moreover, public venture funding has had some major successes in the United States: Apple Computer, Chinron, Compaq, FedEx, and Intel all received support at an early stage from Federal programs. In a more general survey article, Hall (2002) summarizes evidence on the funding gap for $\mathrm{R} \& \mathrm{D}$, and argues that government seed capital and subsidy programs are, at the least, worthy of much more thorough investigation.

How should resources be divided between guarantee schemes and co-funding schemes? Some evidence exists on current, as opposed to best, practice. Li (1998) argues that the division of resources is generally decided politically, suggesting that the benefits of guarantees are spread more evenly across the population than those of co-funding schemes, and hence that they may be easier to legitimize. Li's work also points to dynamic efficiency concerns: if, as she states, credit programs are mostly devices for redistributing cash between sectors that inevitably discourage private saving, then it is reasonable to ask whether their introduction might result in a redistribution of resources towards unproductive rent-seeking. In line with this concern, Johnson and Mitton (2003) presents 


\section{PUBLIC INITIATIVES TO SUPPORT ENTREPRENEURS}

evidence from the Asian financial crisis that indicates that, at least in Malaysia, those with close relationships to the government are more likely to receive government subsidies.

Public support of the entrepreneurial sector clearly has far-reaching welfare and policy implications. Yet surprisingly little formal theoretical work addresses the topic. Williamson (1994) uses two models of adverse selection to do so: in his first, a costly state verification set-up à la Townsend (1978) and Gale and Hellwig (1985), direct government lending simply displaces private lending and hence does not raise welfare. In his second model, in which payoffs are verifiable but borrower types can be determined only using a costly ex ante screening technology, government guarantees can reduce intermediary screening costs, although they never generate a Pareto improvement. Benavente, Galetovic, and Sanhueza (2006) note that, when the guarantee fund disburses too many funds, it will tend to undermine bank screening incentives. Hence its budget constraint should be sufficiently tight. Hainz and Hakenes (2008) examine the relative merits of direct subsidy (cofunding) and indirect support through public banks: politicians may prefer public banks because they avoid windfall gains for entrepreneurs; moreover, using public banks economizes on screening costs and hence may increase welfare.

As we note in our opening remarks, credit guarantees can only enhance welfare if they are introduced in a market where there is credit rationing. We present a model of entrepreneurial financing in which credit is rationed because of moral hazard, rather than adverse selection, problems. In line with prior work by Tirole (2001) and Holmström and Tirole (1997), we consider a cash-constrained entrepreneur, who needs to raise funds to perform a project whose success depends upon the entrepreneur's costly, and unobservable, effort. While a self-financed entrepreneur would work sufficiently hard to guarantee the success of his project, an entrepreneur who relies upon outside finance will work hard only if he is paid sufficiently for succeeding ${ }^{3}$. Hence the moral hazard problem generates additional costs for the investor. If they are sufficiently high, the entrepreneur is denied credit, and the value of the project is lost to society.

The entrepreneur in our model is able to address the credit rationing problem by pledging as collateral personal assets not related to the project. Nevertheless, collateral on its own may be

\footnotetext{
${ }^{3}$ Innes (1990) provides the first detailed treatment of optimal contracting in this situation.
} 


\section{PUBLIC INITIATIVES TO SUPPORT ENTREPRENEURS}

insufficient to generate access to credit market. If this is the case, we show that a credit guarantee can enhance welfare by ensuring that both the entrepreneur's incentive compatibility constraint and the lender's participation constraint can be simultaneously satisfied, so that the project can go ahead.

We also demonstrate that, for sufficiently small guarantees, the borrower's incentives are actually increasing in the size of the guarantee, and hence so is welfare. To understand why this is the case, note that increases in the credit guarantee have two effects. First, they make the financier willing to lend at better terms, and so reduce the entrepreneur's cost of capital; second, because some of the losses from the project are borne by the State, increases in the credit guarantee reduce the jointly efficient effort level for the entrepreneur and the financier. So long as the guarantee is small, the former effect outweighs the latter, and increased guarantees translate into greater entrepreneurial effort. Further increases in the guarantee induce banks to lower their lending standards by substituting public for private collateral. This attenuates the entrepreneur's incentive to exert effort. Hence, our model indicates that, even when state intervention in the credit markets has the potential to increase welfare, it will do so only if the intervention is carefully designed.

One simple policy point emerges from this discussion. In many countries, guarantee agencies are subject to political and other pressures, such as lobbying or outright bribery by entrepreneurs and banks, to deploy all of their resources. To the extent that this is the case, it is important that guarantee agencies are not able to provide support beyond the point at which it starts to damage entrepreneurial incentives. Hence guarantee agencies should be subject to hard budget constraints. A similar point is made for slightly different reasons by Benavente, Galetovic, and Sanhueza (2006).

Even when a credit support agency has a sufficiently tight hard budget constraint, it is still necessary to explain why credit guarantees should ever outperform a co-funding scheme. To see why this might be the case, we extend our model to allow for two types of entrepreneur: productive entrepreneurs, who have potentially valuable projects that require effort to succeed, and "copy-cat" entrepreneurs, who have no productive project. Financial intermediaries are able in our set-up to distinguish between these types of entrepreneur, but the government credit support agency, due to its limited technological expertise, may not. Hence, in our extended model government co-funding 


\section{PUBLIC INITIATIVES TO SUPPORT ENTREPRENEURS}

will cause some resources to be directed to unproductive entrepreneurs. This represents a straightforward redistribution of wealth, which in our model is damaging because it takes resources away from productive entrepreneurs who could make better use of them. In this case, we demonstrate that co-funding is valuable only after the credit support agency has provided the maximum useful level of guarantees.

Hence, a "pecking order" of support schemes emerges from our analysis. If it is welfare enhancing to support the credit markets, then support should be provided first through credit guarantee programs, and second through co-funding schemes. Co-funding schemes should be employed only when credit guarantee programs expand to such an extent that borrowers start to substitute public for private collateral. Co-funding should therefore be seen only in countries that are able to commit relatively large quantities of public funds to supporting private enterprise.

Our extended model yields one simple policy prescription. Credit subsidies and credit guarantees are the product of a single optimization problem, and hence should be designed together. This implies that the guarantee and subsidy agencies should be coordinated, and that they should be subject to a common budget constraint. One simple way to accomplish this would be to delegate guarantee and direct subsidy provision to a single institution.

We consider two further extensions to our model. In the first, we introduce a role for banks as monitors of investments. We show that credit guarantees can ameliorate bank monitoring incentives. Hence, the regulator faces a trade-off between incentivising bank monitoring, and incentivising the entrepreneur. The basic pecking order for entrepreneurial support is however unchanged: regulators still provide credit guarantees ahead of co-funding, but the optimal level of credit guarantee is monotonically decreasing in the cost of bank monitoring.

In the second of our additional extensions, we consider the dynamic efficiency consequences of our model. We allow entrepreneurs to exert effort to find productive projects, and also to uncover cost savings for their projects. We find that well-designed public support programs should foster entrepreneurial innovation. However, public support schemes have a deleterious impact upon (X-) efficiency. This is because credit-constrained entrepreneurs have a strong incentive to find ways to cut costs, because it is only by doing so that they can hope to raise the funds that they need to 


\section{PUBLIC INITIATIVES TO SUPPORT ENTREPRENEURS}

carry out their projects. Public schemes reduce the extent of credit rationing, and hence diminish the entrepreneur's incentive to reduce costs.

The remainder of the paper is organized as follows. Section 2 presents our basic model. We show how public credit schemes can reduce credit rationing, and how they can enhance entrepreneurial incentives. In section 3 we analyze the entry incentives provided by co-funding, and discuss the appropriate mix of co-funding and credit guarantees in a public support package. Section 4 presents extensions of our basic model, and addresses robustness issues. Section 5 concludes.

\section{Basic Model}

We start with a simple model of entrepreneurial financing. In our basic set-up we analyze the design of credit guarantees; we extend our analysis to incorporate co-funding in section 3.

We analyse a model in which there is universal risk-neutrality, and we normalise the riskfree interest rate to zero. We consider a risk-neutral entrepreneur, who is endowed with a single project. The project requires an investment of $I$, and will either succeed, in which case it will return $\Pi>0$, or it will fail, in which case its return will be zero. The probability that the project succeeds depends upon the entrepreneur's effort, which is unobservable and hence uncontractible: if the entrepreneur exerts effort $e \in[0,1]$ then the probability of project success is equal to $e$. The entrepreneur experiences a private cost $\psi(e)$ from effort $e$, where $\psi^{\prime}(\cdot)>0$, and $\psi^{\prime \prime}(\cdot)>0 .{ }^{4} \mathrm{We}$ assume that, in the absence of financing constraints, the project has a positive NPV:

$$
\max _{e}\{e \Pi-\psi(e)\}>I
$$

We write $Q$ for the entrepreneur's endowment of liquid funds for investment in the project, and we assume that $Q<I$, so that the entrepreneur is unable to finance the project himself. ${ }^{5}$ We assume that there are many potential risk neutral banks, that compete à la Bertrand to invest in the project. ${ }^{6}$

\footnotetext{
${ }^{4}$ We also adopt the following technical assumptions, which ensure that the maximization problem is well-behaved, and that it yields interior solutions: $\psi(0)=\psi^{\prime}(0)=0, \psi^{\prime}(1)$ is sufficiently large, and $\psi^{\prime \prime \prime}(e) \geq 0$. A simple cost function $\psi(e)$ satisfying all of these assumptions would be the quadratic cost function $\alpha e^{2}$, with $\alpha$ large enough.

${ }^{5}$ In section 3 we will endogenise $Q$, by allowing the government credit support agency to select it as a co-funding provision.

${ }^{6}$ Bertrand-style competition is appropriate in this model for two reasons. First, the size of a project is fixed, and
} 


\section{PUBLIC INITIATIVES TO SUPPORT ENTREPRENEURS}

Because the entrepreneur is unable to commit to an effort level, it is only possible to incentivise him by offering him a sufficiently high income after project success. When the project is insufficiently profitable to provide an adequate incentive payment, the entrepreneur will never work sufficiently hard and hence, although the project is socially valuable with adequate entrepreneurial effort, it will not be financed.

In addition to any liquid funds $Q$, the entrepreneur is also endowed with some illiquid assets $A$, which he can choose to pledge as collateral against his project. The assets $A$ are not created by the project, but are already owned by the entrepreneur; an example would be the entrepreneur's home. We write $\beta A$ for the level of collateral that the entrepreneur pledges where $\beta \in[0,1]$. Collateral that is pledged will be liquidated in the event of project failure. In our initial model, the only active role for the bank is in enforcing collateral; later in the paper, we discuss an extension in which banks can actively monitor their loans. We assume that there is insufficient collateral to render the bank's claim riskless:

$$
I-Q>A \text {. }
$$

A contract in this set-up consists of a payment $R$, which the entrepreneur makes to the bank in the event of project success, and a level $\beta$ of collateralization, which entitles the bank to seize entrepreneurial assets to the value of $\beta A$ in the wake of project failure. Given a contract $(R, \beta)$, the entrepreneur will derive the following expected utility from an effort level $e$ :

$$
U(R, \beta, e) \equiv e(\Pi+A-R)+(1-e)(1-\beta) A-\psi(e) .
$$

He will therefore select his effort level to satisfy the following first order condition:

$$
\Pi-(R-\beta A)=\psi^{\prime}(e) .
$$

The contract $(R, \beta)$ will beat the bank's outside option, which is the zero risk-free interest rate, precisely when the effort level $e$ that satisfies equation (4) satisfies the following constraint:

$$
e R+(1-e) \beta A \geq I-Q
$$

hence so is the quantity of investment that a bank provides. Second, it is easy for banks to observe one another's interest rate, and to alter their own rate in response. 


\section{PUBLIC INITIATIVES TO SUPPORT ENTREPRENEURS}

In the absence of any form of public subsidy, the entrepreneur will maximize $U(R, \beta, e)$ subject to the incentive compatibility constraint (4), the individual rationality constraint (5), and the requirement that $\beta \in[0,1]$.

We now adopt the following parameter assumption:

Assumption 1. The value of collateral $A$ is sufficiently low to ensure that for every $e \in[0,1]$, condition (6) is satisfied:

$$
I-Q-A>e\left(\Pi-\psi^{\prime}(e)\right)
$$

We demonstrate in lemma 1 that assumption 1 ensures that, without any form of public support, entrepreneurs will be unable to raise finance for their projects. Hence we introduce a public institution into our model that can provide credit guarantees. Under a credit guarantee of strength $\phi \in[0,1]$, an investor in a failed entrepreneurial project receives a payment of $\phi(I-Q)$. The credit support agency awards a guarantee to an entrepreneur, who is then free to use it with whichever bank provides him with funding.

Lemma 1 demonstrates that credit guarantees are necessary to resolve a credit rationing problem.

Lemma 1. Suppose that assumption 1 is satisfied. Then there exists a minimum level of credit guarantee $\underline{\phi}$ such that for levels of guarantee $\phi$ below $\underline{\phi}$, it is impossible to satisfy both the bank's participation constraint and the entrepreneur's incentive compatibility constraint simultaneously. Hence the entrepreneur is credit rationed when $\phi<\underline{\phi}$. For $\phi \geq \underline{\phi}$, the entrepreneur can raise external finance. Moreover, the entrepreneur's effort is initially increasing in $\phi$.

The proof of lemma 1 appears in the appendix. The intuition for the result is however straightforward. With a credit guarantee, the bank's participation constraint (5) becomes:

$$
e R+(1-e)(\beta A+\phi(I-Q)) \geq I-Q
$$

We show below that for sufficiently low $\phi$, the entrepreneur optimally pledges all of his assets as collateral, i.e., $\beta=1$. Because the entrepreneur extracts all of the rent from the project, the bank's 


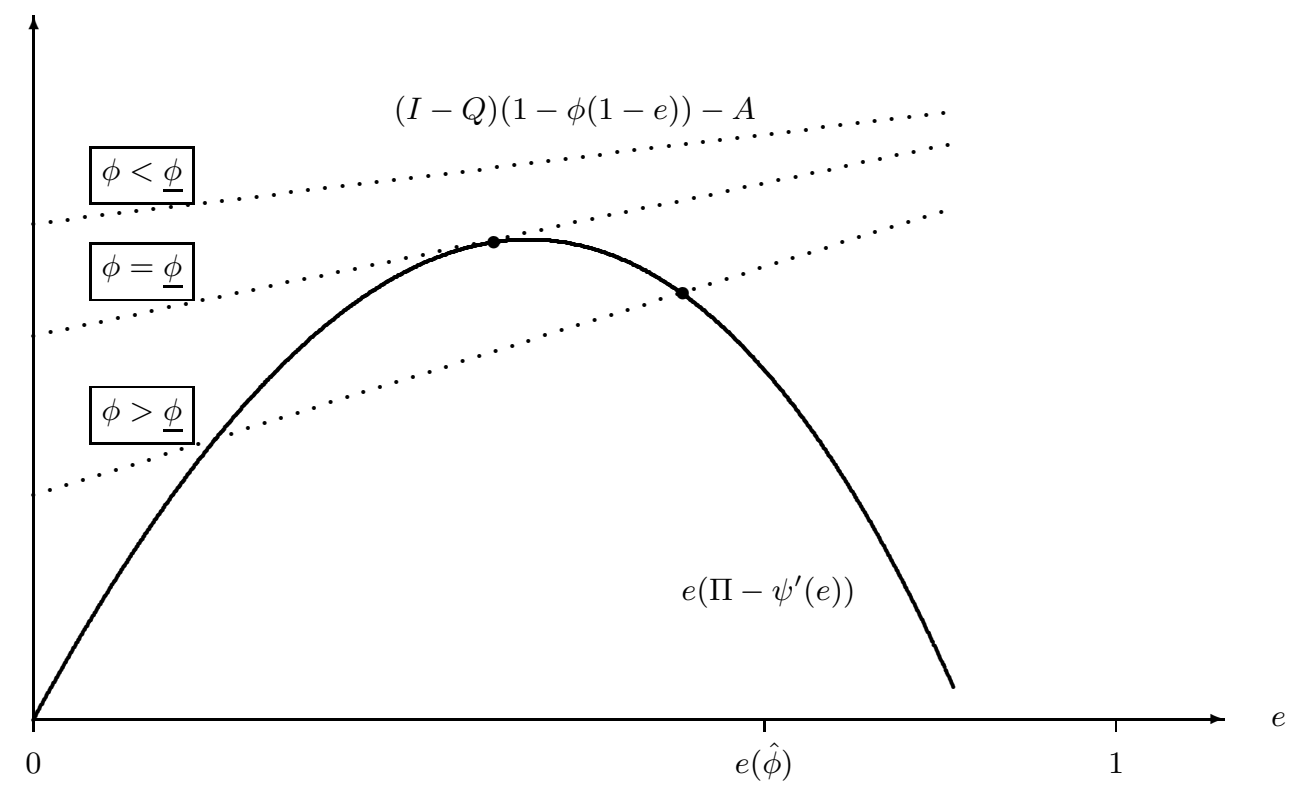

Figure 1: Credit Guarantees, Incentive Compatibility, and Access to Credit. The figure illustrates the incentive compatibility constraint (8). The bold line depicts the term $e\left(\Pi-\psi^{\prime}(e)\right)$, while the dotted lines depict the term $(I-Q)(1-\phi(1-e))-A$ for varying levels $\phi$ of the credit guarantee. The entrepreneur's incentive compatibility constraint is satisfied when the two lines intersect.

participation constraint (7) must bind. Setting $\beta=1$ and using equation (7) to substitute into the incentive compatibility constraint yields the following expression:

$$
e\left(\Pi-\psi^{\prime}(e)\right)=(I-Q)(1-\phi(1-e))-A ;
$$

In other words, the bank's participation constraint and the entrepreneur's incentive constraint can be satisfied simultaneously precisely when there exists $e \in[0,1]$ satisfying equation (8); when no such $e$ exists, the entrepreneur cannot raise financing.

Equation (8) is illustrated in figure 1; the bold line depicts the left hand side of the equation, and the dotted lines depict the right hand side for various levels of credit guarantee, $\phi$. For $\phi<\underline{\phi}$ the two lines do not meet, and hence financing is impossible. For values of $\phi$ above $\underline{\phi}$ but still sufficiently low for the collateral level $\beta$ optimally to be set equal to 1 , an equilibrium with lending 


\section{PUBLIC INITIATIVES TO SUPPORT ENTREPRENEURS}

occurs at the point where the two lines meet. Increases in $\phi$ shift the dotted line down, without affecting the solid line. Hence, provided $\beta=1$, increases in $\phi$ shift the intersection point to the right, and with it the equilibrium effort level.

Lemma 1 states that, for low enough $\phi$, entrepreneurial effort in a lending equilibrium is increasing in $\phi$. Proposition 1 provides a complete characterization of equilibria with credit guarantees.

Proposition 1. Suppose that an entrepreneur has internal funds $Q$ and a credit guarantee of $\phi(I-Q)$. Define $\hat{\phi}(Q)$ as follows:

$$
\hat{\phi}(Q) \equiv 1-\frac{A}{I-Q}
$$

and notice that $\underline{\phi}<\hat{\phi}(Q)$. Then:

1. For $\phi<\phi$, the entrepreneur is credit-rationed (lemma 1);

2. For $\underline{\phi} \leq \phi<\hat{\phi}(Q)$, the optimal contract is as follows:

$$
\begin{aligned}
& \beta=1 \\
& R=\frac{1}{e}\{(I-Q)(1-\phi(1-e))-(1-e) A\},
\end{aligned}
$$

where the effort level e solves equation (8). For these levels of guarantee, entrepreneurial effort is increasing in $\phi$;

3. For $\phi \geq \hat{\phi}(Q)$, the optimal contract is as follows:

$$
\begin{aligned}
& \beta=\frac{(I-Q)(1-\phi)}{A}<1 ; \\
& R=I-Q,
\end{aligned}
$$

where the effort e solves equation

$$
\psi^{\prime}(e)=\Pi-\phi(I-Q)
$$

For these levels of guarantee, entrepreneurial effort is decreasing in $\phi$. 


\section{PUBLIC INITIATIVES TO SUPPORT ENTREPRENEURS}

Proposition 1 is proved in the appendix. Its intuition is as follows. As in lemma 1, no credit is extended for $\phi<\phi$. For higher $\phi$ the bank is prepared to invest. The effect of an increase in the credit guarantee on the entrepreneur's incentive to exert effort then hinges upon the relative importance of two opposing effects. First, an increase in the credit guarantee makes the bank willing to lend at better terms, and so reduces the entrepreneur's cost of capital. This makes it easier to induce the entrepreneur to exert high effort. Second, because some of the losses from the project are borne by the credit support agency, an increase in the credit guarantee reduces the jointly efficient effort level for the entrepreneur and the financier. So long as the guarantee is small, the former effect outweighs the latter, and increased guarantees translate into greater entrepreneurial effort. For higher levels of guarantee, the second effect is dominant: at these levels of guarantee, the jointly efficient effort level is so small such that the effort level that the entrepreneur would exert if the contract were fully collateralized would actually exceed the jointly efficient effort level. To ensure that the entrepreneur does not overexert effort, the optimal contract stipulates that the loan is partially, rather than fully, collateralized. In equilibrium, the entrepreneur exerts the jointly efficient level, which happens to be decreasing in the credit guarantee due to its put option feature. The proposition is illustrated in figure 2 .

\section{Credit Guarantees and Co-Funding}

In section 2 we demonstrate that credit guarantees can help to resolve the credit rationing problem that arises when entrepreneurial effort levels are not observable, and hence are non-contractible. But it is reasonable to ask what is special about a credit guarantee: a system of co-funding under which the credit support agency made investments that increased the entrepreneur's level $Q$ of internal funds would also raise welfare, and would not impair incentives. In practice, of course, co-funding could result in excessive entrepreneurial entry if it attracted copy-cat entrants without a productive project: this would restrict the supply of funds to productive entrepreneurs. In this section, we examine the optimal mix of credit guarantee provision and co-funding in a world where entry by unproductive entrepreneurs is possible. We adopt the simplest possible framework in which entry of this type can be modelled, by endowing our unproductive entrepreneurs with a 


\section{PUBLIC INITIATIVES TO SUPPORT ENTREPRENEURS}

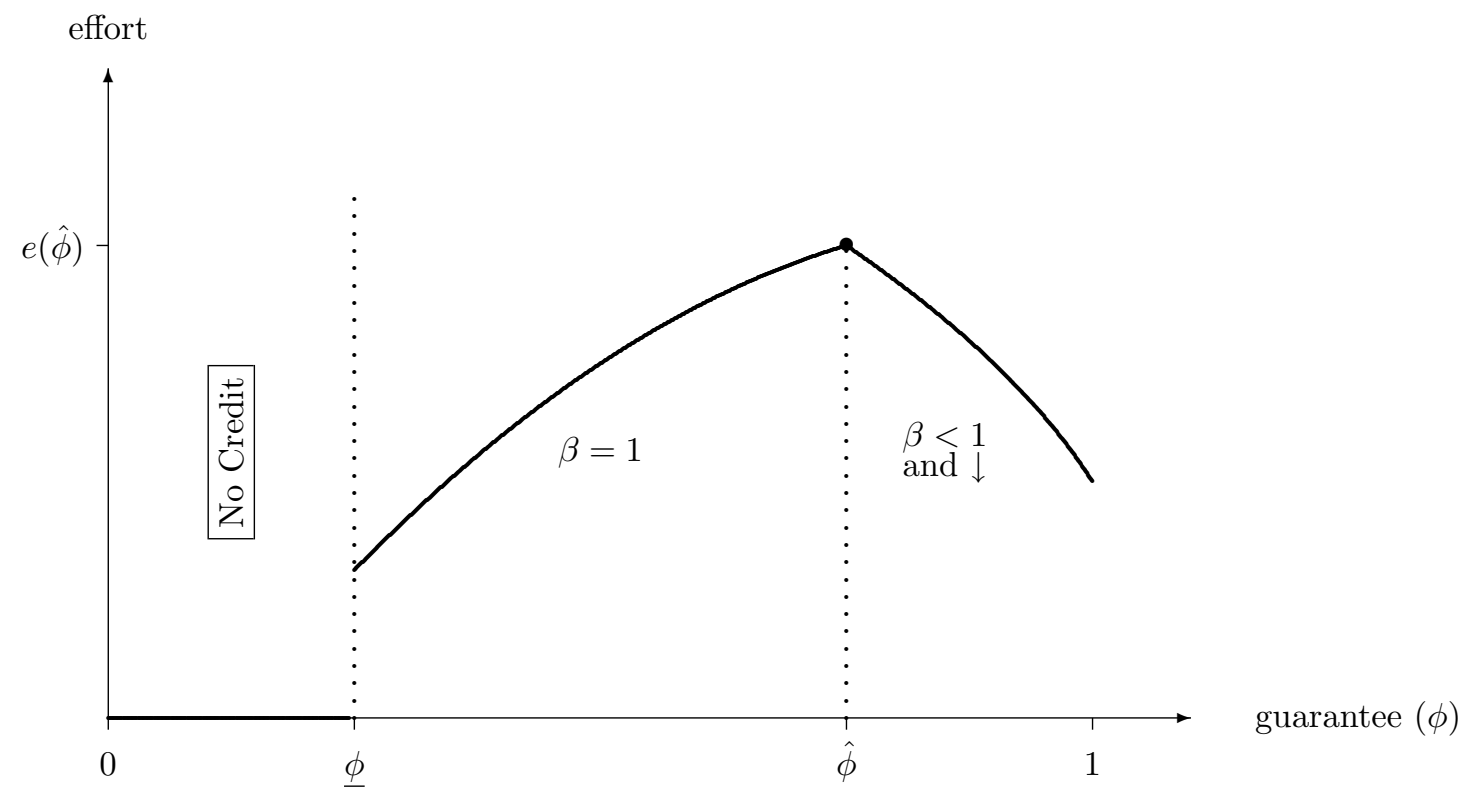

Figure 2: Credit guarantees and effort incentives. No lending occurs for $\phi<\underline{\phi}$, fully collateralized lending with effort increasing in $\phi$ occurs for $\phi \leq \phi<\hat{\phi}(Q)$, and partially collateralized lending with collateral levels and effort both dropping in $\phi$ occurs for $\hat{\phi}(Q) \leq \phi \leq 1$.

riskless zero NPV project. We consider the robustness of our results to this assumption in section 4.3 .

We now assume that there is a unit mass of productive entrepreneurs, each of whom has no internal funds, illiquid collateralizable assets of $A$, and a project of the type analyzed in the previous section. There is also a mass $\xi \leq 1$ of copy-cat entrepreneurs, each of whom has a safe zero NPV project, and derives a small private benefit from running it. Although banks in our set-up can distinguish between productive and copy-cat entrepreneurs, we assume that the credit support agency, due to its limited technological expertise, is only imperfectly able to do so. Specifically, we assume that the credit support agency is able to identify a copy-cat entrepreneur with probability $\theta$ when evaluating a support request, while with probability $1-\theta$ it is not able to so. Banks may derive their informational advantage over the government from a better screening technology, or from tacit information gathered through their relationship with the entrepreneur. ${ }^{7}$

Banks are prepared to invest so long as they break even. Hence, because they have riskless

\footnotetext{
${ }^{7}$ A large empirical literature suggests that banks do indeed have special information about their borrowers. See for example James (1987), Datta, Iskandar-Datta, and Patel (1999), and Ongena, Roscovan, and Werker (2007).
} 


\section{PUBLIC INITIATIVES TO SUPPORT ENTREPRENEURS}

zero NPV investment opportunities, copy-cat entrepreneurs with support from the credit agency can attract bank finance. The mass of copy-cat entrepreneurs being able to attract co-funding is then given by $\rho=\xi(1-\theta)$. Hence, the lower the credit support agency's technological expertise, the larger will be the transfer of wealth to unproductive copy-cat entrepreneurs. Notice that while copy-cat entrepreneurs may attract co-funding, they do not benefit from credit guarantees. This is because their projects are risk-free, and hence they cannot possibly go bankrupt.

Two strategies are available to the credit support agency. First, it can co-fund, in which case it provides the entrepreneur with co-funding $Q$; second, it can provide a credit guarantee of $\phi(I-Q)$, as in section 2. We assume that the credit support agency faces the following budget constraint:

$$
\underbrace{\rho Q}_{\begin{array}{c}
\text { Funds allocated to } \\
\text { copy-cat investors }
\end{array}}+\underbrace{Q+(1-e)(I-Q) \phi}_{\begin{array}{c}
\text { Funds allocated to } \\
\text { productive entrepreneurs }
\end{array}} \leq B<(1+\rho)(I-A) \equiv \bar{B},
$$

where $B$ is the credit support agency's budget. To see why we assume $B<\bar{B}$, notice that if the credit support agency had financial resources $B \geq \bar{B}$, then the fund would be able to implement the first best by offering co-funding $Q=I-A$ to every entrepreneur. Assuming that $B<\bar{B}$ allows us to rule out this rather uninteresting case.

Given a support package $(Q, \phi)$ from the credit support agency, a productive entrepreneur will solve the problem analyzed in section 2 . The credit support agency therefore selects $(Q, \phi)$ to solve

$$
\begin{aligned}
\max _{\{Q, \phi\}} & e(Q, \phi) \Pi-\psi(e(Q, \phi)) \\
\text { s.t. } & \\
& \rho Q+Q+(1-e(Q, \phi))(I-Q) \phi \leq B \\
& \phi \leq \hat{\phi}(Q)=1-\frac{A}{I-Q}
\end{aligned}
$$

where $e(Q, \phi)$ is characterized by expression (8).

The solution to the credit support agency's problem is described in Proposition 2.

Proposition 2. Suppose that there is a fixed mass 1 of productive entrepreneurs, that there is a mass $\rho$ of unproductive copy-cat entrepreneurs, that no entrepreneur has any wealth, and that the credit support agency is able to provide co-funding or credit guarantees, subject to the budget 


\section{PUBLIC INITIATIVES TO SUPPORT ENTREPRENEURS}

constraint (14). Define

$$
\underline{B} \equiv(1-e(0, \hat{\phi}(0))(I-A)
$$

Then:

1. If $B<\underline{B}$ then the credit support agency should provide no co-funding, and should provide the maximum credit guarantee consistent with its budget constraint, i.e., $Q=0$ and $\phi=$ $B /((1-e) I)$, where $e$ is the largest solution of

$$
\psi^{\prime}(e)=\Pi-\frac{I-A-B}{e}
$$

2. If $B \geq \underline{B}$ then the credit support agency should provide co-funding

$$
Q=\frac{B-(1-e)(I-A)}{\rho+e}
$$

and a credit guarantee of $\hat{\phi}(Q)=1-A /(I-Q)$, where $e$ is the largest solution of

$$
\psi^{\prime}(e)=\Pi-(I-Q-A)
$$

In the limit, as $B$ approaches $\bar{B}$, we have $Q=I-A$ and $\phi=0$.

The proof of Proposition 2 appears in the appendix. To understand the result, note first that credit guarantees are used to subsidize productive projects only, while co-funding induces entry by unproductive copy-cat entrepreneurs, who therefore take a proportion of any co-funding. Hence, if the credit support agency faces a very tight budget constraint, then it should provide no co-funding and spend its entire resources on credit guarantees. As the credit support agency's budget increases, it will continue to devote its entire resources to guarantees up to the point where the level of guarantee hits the incentive-compatibility threshold $\hat{\phi}(0)$. As the credit support agency's budget increases beyond $\underline{B}$, its budget constraint would be slack if it continued to provide a guarantee of $\hat{\phi}(0)$ and no co-funding. The credit support agency responds by devoting some resources to cofunding, but at the same time reducing the guarantee to $\hat{\phi}(Q)<\hat{\phi}(0)$. The amount of co-funding is then increasing in the credit support agency's budget, while the level of guarantee is decreasing.

It is worth noting that an increase in the value of the collateral $A$ leads to a decrease in the level of guarantee when the credit support agency operates under a sufficiently generous budget 


\section{PUBLIC INITIATIVES TO SUPPORT ENTREPRENEURS}

constraint. The reason for that is that with high private collateral value a lower level of guarantee is needed to achieve the jointly efficient effort level for the entrepreneur and the bank. At the same time, given the fund's budget a higher $A$ also results in more co-funding. The fund's technological expertise, measured by $\rho$, affects the design of the support package. In particular, we find that funds with more expertise should provide more co-funding and, correspondingly, less guarantees.

Note that the analysis of this section is predicated upon the assumption that a single agency is responsible both for direct subsidies of investment, in the form of co-funding, and also for the provision of credit guarantees. Only when this is the case can the optimal joint policy be adopted: if the two forms of entrepreneurial support are not subject to a single budget constraint then there is no a priori reason to assume that correct policies will be adopted. Hence our analysis indicates that governments should optimally combine the provision of credit guarantees and of co-funding within a single agency.

\section{Extensions and Robustness}

In this section we discuss some possible extensions to our model, and address some robustness issues.

\subsection{Monitoring}

The only active role played by the banks in our basic set-up is in realizing collateral assets. In reality, it is well-understood that banks play a valuable role as active monitors of entrepreneurs: banks that form close relationships with the entrepreneurs to whom they lend are in a position to influence their activities. ${ }^{8}$ If monitoring is important, it is therefore critical that the State does not undermine monitoring incentives when it creates support schemes. In this section, we extend our analysis with a very simple model of bank monitoring, and we show that that our intuitions are not affected.

Suppose that monitoring is required to prevent the entrepreneur from diverting resources for

\footnotetext{
${ }^{8}$ See for example Diamond (1984), James (1987) and Datta, Iskandar-Datta, and Patel (1999).
} 


\section{PUBLIC INITIATIVES TO SUPPORT ENTREPRENEURS}

private consumption. The bank can prevent resource diversion, but cannot compel the entrepreneur to exert a high effort, so that entrepreneurial incentive compatibility remains important. We reflect these assumptions in our set-up by assuming that the success probability of the project is $\sigma e$, where $\sigma \in\{0,1\}$, with $\sigma=1$ precisely when the bank monitors; as before, $e$ denotes entrepreneurial effort.

In line with Holmström and Tirole (1997), we assume that banks sacrifice a private benefit $P>0$ when they monitor. It follows that banks will only monitor if it is sufficiently profitable for them to do so. When the opportunity cost $P$ to the bank of monitoring is sufficiently high, they may never elect to monitor with the contracts studied in sections 2 and 3. Nevertheless, because monitoring raises surplus, banks would prefer ex ante to commit to monitor. They can do so by lending the entrepreneur more than is needed to finance the project: we write $T>0$ for the size of the additional transfer. In exchange for $T$, the entrepreneur commits to repay more to the bank in the event of project success. This larger payment generates incentives for the bank to monitor.

We start by following the analysis of section 2. Let $Q$ be the entrepreneur's endowment of liquid funds, and suppose that the State provides a credit guarantee of strength $\phi$. In this case, the entrepreneur wishes to maximize $U(R, \beta, e)+T$ subject to the entrepreneurial incentive compatibility constraint (4), a non-negativity requirement on $T$, the bank's participation constraint (17), and the bank's monitoring incentive compatibility constraint (18):

$$
\begin{gathered}
e R+(1-e)(\phi(I-Q)+\beta A) \geq I-Q+T \\
e(R-\phi(I-Q)-\beta A) \geq P .
\end{gathered}
$$

If the monitoring incentive compatibility constraint (18) is slack at the contract described in proposition 1 then this remains the optimal contract with monitoring. To make the analysis more interesting, we assume that this is the case at $\phi=\underline{\phi}$, and that it is not the case at $\phi=\hat{\phi}$. Hence

there exists a $\tilde{\phi} \in(\underline{\phi}, \hat{\phi})$ such that constraint (18) is slack if and only if $\phi \leq \tilde{\phi}$. When $\phi \in[\underline{\phi}, \tilde{\phi}]$, part 2 of proposition 1 implies that $\beta=1$. Hence we use equation (17) to substitute for the left hand side of equation (18), which yields condition (19):

$$
(1-\phi)(I-Q)-A \geq P
$$




\section{PUBLIC INITIATIVES TO SUPPORT ENTREPRENEURS}

It follows immediately that $\tilde{\phi}=1-\frac{A+P}{I-Q}$.

For $\phi>\tilde{\phi}$, we can no longer use proposition 1 to set $\beta$ equal to 1 . Re-arranging equations (17) and (18) then gives us

$$
\begin{aligned}
& R=\phi(I-Q)+\frac{P}{e}+\beta A ; \\
& T=P-(1-\phi)(I-Q)+\beta A,
\end{aligned}
$$

and the first of these expressions can be used to re-write the entrepreneurial incentive constraint (4) as

$$
\Pi-\phi(I-Q)-\frac{P}{e}=\psi^{\prime}(e)
$$

Equations (20) - (22) do not yield unique solutions for $T$ and $\beta$. Rather than characterize the solution set for the equations, we simply note that it is obvious from equation (22) that, for a given $Q, e$ is decreasing in $\phi$ for $\phi \geq \tilde{\phi}$. We know from proposition 1 that $e$ is increasing in $\phi$ for $\phi<\tilde{\phi}$. In other words, the credit support agency will never select $\phi>\tilde{\phi}$.

More specifically, notice that, in selecting the support package $(Q, \phi)$, the credit support agency faces a problem that is analogous to the one analyzed in section 3 , with constrain 16 replaced by the following condition:

$$
\phi \leq \tilde{\phi}(Q) \equiv 1-\frac{A+P}{I-Q}
$$

This discussion yields the following proposition:

Proposition 3. Suppose that it is necessary to incentivize bank monitoring, and define

$$
\underline{\tilde{B}} \equiv(1-\hat{e}(0, \tilde{\phi}(0)))(I-A-P)
$$

Then:

1. If $B<\underline{\tilde{B}}$ then the credit support agency should provide no co-funding, and should provide the maximum credit guarantee consistent with its budget constraint. That is, $Q=0$ and $\phi=B /((1-e) I))$, where $e$ is the largest solution of

$$
\psi^{\prime}(e)=\Pi-\frac{I-A-B}{e}
$$




\section{PUBLIC INITIATIVES TO SUPPORT ENTREPRENEURS}

2. If $B \geq \underline{\tilde{B}}$ then the credit support agency should provide co-funding

$$
Q=\frac{B-(1-e)(I-A-P)}{\rho+e}
$$

and a credit guarantee of $\tilde{\phi}(Q)=1-(A+P) /(I-Q)<\hat{\phi}(Q)=1-A /(I-Q)$, where $e$ is the largest solution of

$$
\psi^{\prime}(e)=\Pi-(I-Q-A)-\frac{1-e}{e} P
$$

The proof of the proposition 3 is similar to that of proposition 2, and is therefore omitted. Proposition 3 demonstrates that introducing bank monitoring into our model shifts the trade-off between guarantees and co-funding in favor of co-funding. This is because the budget threshold $\underline{\tilde{E}}$, at which the credit support agency begins to devote resources to co-funding, is decreasing in the cost $P$ of bank monitoring. Furthermore, the level of the guarantee is weakly decreasing, and the level of co-funding is weakly increasing, in the cost of monitoring. The basic pecking order of support identified in Section 3 remains valid. In particular, when the credit support agency's budget is relatively small, it devotes all of its resources to guarantees. As the credit support agency's budget increases it eventually devotes some resources to co-funding and at the same time reduces the level of the guarantee.

\subsection{Dynamic Efficiency}

We have shown that properly designed government support schemes can ensure that lenders' participation constraints are satisfied, while providing entrepreneurs with better effort incentives. But our analysis thus far has taken place in a one-period model and, as we noted in the introduction, several authors have expressed concern that a system of public support to private entrepreneurs may have damaging long-term effects. In particular, if public funds are channeled towards entrepreneurial projects, entrepreneurs may be less concerned to manage costs. On the other hand, if innovation improves access to public subsidies, public support may encourage entrepreneurs to be creative. In this section we present a simple extension of our basic model in which we can analyze this trade-off.

We suppose that entrepreneurs make unobservable effort decisions along two dimensions. First, 


\section{PUBLIC INITIATIVES TO SUPPORT ENTREPRENEURS}

they select an innovation effort $a \in[0,1]: a$ is the probability that the entrepreneur uncovers a productive project. Second, entrepreneurs select a cost-cutting effort $b \in[0,1]: b$ is the probability that the investment outlay for a productive project is low, rather than high. For the sake of simplicity, we assume that, conditional upon finding a productive project, an entrepreneur who exerts cost-cutting effort $b$ will have an investment outlay of zero with probability $b$, and will otherwise have an investment outlay of $I>0$. Entrepreneurs select the effort levels $(a, b)$ that they devote to innovation cost-cutting at the start of the game, and the outcome of their efforts realizes before the funding stage. The cost to the entrepreneur of an effort pair $(a, b)$ is $c(a, b)$, where $c(\cdot, \cdot)$ is increasing in both arguments, and is strictly convex.

Three types of entrepreneurs emerge in this setting. Type 1 entrepreneurs have a productive project that requires external funding; type 2 entrepreneurs have a productive project but do not require external funding; and type 3 entrepreneurs do not have a productive project. An entrepreneur that makes effort choice $(a, b)$ will be of type 1 with probability $a(1-b)$, of type 2 with probability $a b$, and of type 3 with probability $1-a$.

In line with the analysis of section 3, we assume that banks are able to distinguish between the various types of entrepreneurs, but that the credit support agency is not. We also assume that entrepreneurs are not able to enter bogus contracts with banks that are merely intended to induce bankruptcy. Hence, type 2 and 3 entrepreneurs do not benefit from guarantee schemes, but they are able to access co-funding provided by the credit support agency.

With these informational assumptions, the type 1 entrepreneurs in this set-up correspond to the productive entrepreneurs of section 3. Both type 2 and type 3 entrepreneurs do not require public funds. Hence, any funds that they extract from the credit support agency result in a needless crowding-out of the productive type 1 entrepreneurs, who require the assistance of the credit support agency. Hence the combined type 2 and type 3 entrepreneurs play the same role in this section as the copy-cat entrepreneurs of section 3: when the credit support agency has a hard budget constraint, they reduce the quantity of funds that can be distributed to type 1 entrepreneurs, and so reduce the effectiveness of credit support schemes.

Now suppose that entrepreneurs anticipate that a support package $(Q, \phi)$ will become available 


\section{PUBLIC INITIATIVES TO SUPPORT ENTREPRENEURS}

at the funding stage. A type 2 entrepreneur does not require outside finance and therefore reaps the total product of his investment. As a result, he exerts the first best effort level $e^{F B}$ and hence earns an expected continuation payoff, net of personal assets $A$, of

$$
V_{2} \equiv e^{F B} \Pi-\psi\left(e^{F B}\right)+Q
$$

A type 1 entrepreneur will earn the following continuation payoff

$$
V_{1} \equiv e^{*} \Pi+\left(1-e^{*}\right) \phi(I-Q)-\psi\left(e^{*}\right)-I+Q
$$

where $e^{*}$ is the equilibrium managerial effort level from section $3 . V_{1}$ is the sum of the project's net present value net of effort costs and the expected subsidy.

Entrepreneurs therefore select effort levels $(a, b)$ in order to maximize the following objective function:

$$
V(a, b) \equiv a\left(b V_{2}+(1-b) V_{1}\right)+(1-a) Q-c(a, b) .
$$

Proposition 4 shows how effort $(a, b)$ varies with public support.

Proposition 4. Provided the cost function $c(\cdot, \cdot)$ is sufficiently convex, public support strengthens entrepreneurial innovation incentives and diminishes cost-cutting incentives.

This result is proved in the appendix. The intuition is straightforward. Public support initiatives reduce the cost of capital to type 1 entrepreneurs, and hence increase the expected value of a productive project. This effect strengthens entrepreneurs' incentive to innovative. At the same time, however, public support reduces the proportion of the project's costs borne by the entrepreneur, and so impairs his incentives to uncover cost savings so as to diminish the financial constraints that he faces.

\subsection{Risky Copy-Cat Projects}

The copy-cat entrepreneurs in section 3 are not risky. Hence they can benefit from co-funding opportunities, but not from credit guarantees. As a result, credit guarantees are a more effective way of using the limited resources of the guarantee fund, because they direct those resources towards productive projects. 


\section{PUBLIC INITIATIVES TO SUPPORT ENTREPRENEURS}

Suppose instead that copy-cat entrepreneurs were endowed with risky, negative NPV projects. In this case, they would be in a position to profit from the put option provided by the credit guarantee fund. If they were riskier than the productive entrepreneurs then the relative cost in terms of resources diverted to unproductive uses of credit guarantees would exceed that of co-funding. In this case, our simple model appears to suggest that the credit support agency should concentrate upon co-funding.

We do not think that this conclusion is entirely appropriate. The argument of the previous paragraph ignores the screening abilities of banks. Give that the bank is able to identify negative NPV projects, it seems unlikely that it would advance credit for such a project. Indeed, the bank would not advance credit, provided the credit guarantee were not so high that it compensated for the negative NPV of the project. While we think it unlikely that a guarantee of this magnitude would arise in practice, we cannot exclude the possibility that credit support by the State would result in the financing of low quality investment projects that would not have been undertaken in the absence of credit guarantees. If this were to happen, an additional policy trade-off between the costs and benefits of public credit support would arise, in addition the those analyzed formally in this paper.

\subsection{Institutional Issues}

We assume throughout our discussion that the credit support agency distributed funds equally amongst qualifying borrowers. However, as stated in our introduction, there is some evidence that suggests that some agencies may use their funds to finance government cronies. If this is the case then credit support for the entrepreneurial sector may have damaging dynamic effects not considered in section 4.2, in the form of rent-seeking, as productive assets are diverted towards grant-extraction (see Tullock (1967) and Krueger (1974) for the classic expositions of this problem). When these effects are sufficiently pronounced, they may completely outweigh the benefits that we identify in this paper.

These observations do not obviate our conclusions. They do, however, suggest some preconditions for our conclusions to be valid. First, public support for private entrepreneurs should be 


\section{PUBLIC INITIATIVES TO SUPPORT ENTREPRENEURS}

provided by an agency that is sufficiently removed from the government of the day. Second, the credit support agency should be forced to publish and to follow objective criteria for the allocation of loans, even if these criteria are second-best. More generally, public support for private business is unlikely to work in a country with weak institutions, and where the rule of law is weak.

\section{Conclusion}

We study public initiatives to support entrepreneurs when they are capital-constrained, suffer from a moral hazard-induced principal-agent problem, and are able to pledge costly collateral. In this set-up, credit guarantee schemes can raise welfare, because they reduce the bank's need to extract success-state payouts from entrepreneurs, and so enhance entrepreneurial effort incentives. At the same time, excessively generous guarantee schemes could cause entrepreneurs to substitute public for private collateral, so so undermine their effort incentives. Co-funding entrepreneurs does not cause this problem, but, irrespective of its level, it does result in excessive entrepreneurial entry. Hence we derive a "pecking order" for entrepreneur support schemes: the State should concentrate its resources upon credit guarantees up to the point where they cause entrepreneurs to substitute away from their own collateral; only at this point should the State devote resources to co-funding. Credit guarantees undermine bank monitoring incentives; we show in an extension to our basic model that, although bank monitoring does not affect the basic pecking order for State support, the optimal credit guarantee level is monotonically decreasing in the cost of monitoring.

Our model points to a number of ways in which state support of the entrepreneurial sector can raise welfare. Nevertheless, there are some caveats to our reasoning. In a dynamic version of our model, public support may weaken incentives to cut costs in favour of those to innovate; the welfare consequences of this effect are unclear. Our results rely upon an assumption that banks can screen out the worst borrowers ex ante, and that they have the incentives to do so. And finally, we note that state support for the entrepreneurial sector is likely to be damaging in countries whose legal and political institutions are under-developed. A more complete analysis of these points is left for further work. 
PUBLIC INITIATIVES TO SUPPORT ENTREPRENEURS

\section{References}

Banerjee, A. \& E. Duflo (2004), 'Do Firms Want to Borrow More? Testing Credit Constraints Using a Directed Lending Program', Discussion Paper 4681, Centre for Economic Policy Research, London, UK.

Beck, T., L. F. Klapper \& J. C. Mendoza (2008), 'The Typology of Partial Credit Guarantee Fund around the World:', Mimeo, World Bank, Washington, DC.

Benavente, J. M., A. Galetovic \& R. Sanhueza (2006), 'Fogape: An Economic Analysis', Working Paper 222, University of Chile, Santiago, Chile.

Columba, F., L. Gambacorta \& P. E. Mistrulli (2008), 'Firm as Monitors of Other Firm: Mutual Loan Guarantee Consortia and SME Finance', mimeo, Bank of Italy.

Datta, S., M. Iskandar-Datta \& A. Patel (1999), 'Bank Monitoring and the Pricing of Corporate Debt', Journal of Financial Economics, Vol. 51, pp. 435-449.

Diamond, D. W. (1984), 'Financial Intermediation and Delegated Monitoring', Review of Economic Studies, Vol. 51, No. 3 (July), pp. 393-414.

Fazzari, S. M., R. G. Hubbard \& B. C. Petersen (1988), 'Financing Constraints and Corporate Investment', Brookings Papers on Economic Activity, Vol. 1988, No. 1, pp. 141-195.

Gale, D. \& M. Hellwig (1985), 'Incentive-Compatible Debt Contracts: The One Period Problem', Review of Economic Studies, Vol. 52, No. 4 (October), pp. 647-663.

Gudger, M. (1998), Credit Guarantees: An Assessment of the State of Knowledge and New Avenues of Research, Food and Agriculture Organization, United Nations.

Hainz, C. \& H. Hakenes (2008), 'The Politician and his Banker', Collectve Goods Preprint 2008/1, Max Planck Institute for Research on Collective Goods, Bonn.

Hall, B. H. (2002), 'The Financing of Research and Development', Oxford Review of Economic Policy, Vol. 18, No. 1 (Spring), pp. 35-51. 
PUBLIC INITIATIVES TO SUPPORT ENTREPRENEURS

Hancock, D., J. Peek \& J. A. Wilcox (2007), 'The Repercussions on Small Banks and Small Businesses of Bank Capital and Loan Guarantees', Working Paper 07-22, Financial Institutions Center, Wharton University.

Holmström, B. \& J. Tirole (1997), 'Financial Intermediation, Loanable Funds and the Real Sector', Quarterly Journal of Economics, Vol. 112, No. 3 (August), pp. 663 - 691.

Hoshi, T., A. Kashyap \& D. Scharfstein (1990), 'Corporate Structure, Liquidity and Investment: Evidence from Japanese Industrial Groups', Quarterly Journal of Economics, Vol. 106, pp. 33-60.

Hubbard, R. G. (1998), 'Capital-Market Imperfections and Investment', Journal of Economic Literature, Vol. 36, No. 1 (March), pp. 193-225.

Innes, R. D. (1990), 'Limited Liability and Incentive Contracting with Ex-Ante Action Choices', Journal of Economic Theory, Vol. 52, No. 1 (October), pp. 45-67.

James, C. (1987), 'Some Evidence on the Uniqueness of Bank Loans', Journal of Financial Economics, Vol. 19, No. 2, pp. 217-235.

Johnson, S. \& T. Mitton (2003), 'Cronyism and Capital Controls: Evidence From Malaysia', Journal of Financial Economics, Vol. 67, No. 2 (February), pp. 351-382.

Krueger, A. O. (1974), ‘The Political Economy of the Rent-Seeking Society’, American Economic Review, Vol. 64, No. 3 (June), pp. 291 - 303.

Lelarge, C., D. Sraer \& D. Thesmar (2008), 'Entrepreneurship and Credit Constraints: Evidence from a French Loan Guarantee Program’, Technical report, University of California.

Lerner, J. (1999), 'The Government as Venture Capitalist: The Long-Run Impact of the SBIR Program', Journal of Business, Vol. 72, No. 3 (July), pp. 285-318.

Li, W. (1998), 'Government Loan, Guarantee, and Grant Programs: An Evaluation', Federal Reserve Bank of Richmond Economic Quarterly, Vol. 84, No. 4 (Fall), pp. 25-51.

OECD (1997), 'Government Venture Capital for Technology-Based Firms', Technical Report OCDE/GD(97)201, Organisation for Economic Co-Operation and Development, Paris. 
Ongena, S., V. Roscovan \& B. J. Werker (2007), 'Banks and Bonds: The Impact of Bank Loan Announcements on Bond and Equity Prices', Working paper, Tilburg Unviersity.

Tirole, J. (2001), 'Corporate Governance', Econometrica, Vol. 69, No. 1 (January), pp. 1-35.

Townsend, R. M. (1978), 'Optimal Contracts and Competitive Markets with Costly State Verification', Journal of Economic Theory, Vol. 21, No. 2 (October), pp. 265-93.

Tullock, G. (1967), 'The Welfare Costs of Tariffs, Monopolies, and Theft', Western Economic Journal, Vol. 5, No. 3 (June), pp. $224-232$.

Uesugi, I., K. Sakai \& G. M. Yamashiro (2006), 'Effectiveness of Credit Guarantees in the Japanese Loan Market', Discussion Paper 06-E-004, Research Institute of Economy, Trade and Industry.

Wilcox, J. A. \& Y. Yasuda (2008), ‘Do Government Loan Guarantees Lower, Or Raise, Bank’ NonGuaranteed Lending? Evidence from Japanese Banks', mimeo, Hass School of Business, University of California, Berkley.

Williamson, S. D. (1994), 'Do Informational Frictions Justify Federal Credit Programs?', Journal of Money, Credit and Banking, Vol. 26, No. 2 (August), pp. 523-544.

Zecchini, S. \& M. Ventura (2006), 'Public Credit Guarantees and SME Finance', Working Paper 73, ISAE, Rome, Italy.

Zia, B. H. (2008), 'Export Incentives, Financial Constraints, and the (Mis)Allocation of Credit: Micro-Level Evidence from Subsidized Export Loans', Journal of FInancial Economics, Vol. 87, No. 2 (February), pp. 498-527.

\section{Appendix}

\section{Proof of Lemma 1}

The proof procedes as follows. We start by stating the entrepreneur's formal optimization problem. The existence of $\underline{\phi}$ then follows from manipulation of the entrepreneur's incentive compatibility constraint. We finally demonstrate that, for low enough $\phi, e$ is increasing in $\phi$. 


\section{PUBLIC INITIATIVES TO SUPPORT ENTREPRENEURS}

To derive the entrepreneir's optimization problem, recall first that the investor's IR constraint

with a credit guarantee $\phi$ is given by equation (7). Since the entrepreneur extracts all of the surplus from the project, this condition must bind, so that we can re-write the objective function (3) as follows:

$$
U(\beta, e) \equiv e \Pi+A-(I-Q)(1-\phi(1-e))-\psi(e),
$$

and the incentive compatibility constraint (4) as follows:

$$
\Pi-\psi^{\prime}(e)-\frac{(I-Q)(1-\phi(1-e))-\beta A}{e}=0 .
$$

The entrepreneur's problem is therefore to maximize $U(\beta, e)$ subject to the IC constraint (26) and the following limited liability constraint:

$$
\beta \leq 1
$$

We write $\lambda$ and $\mu$ for the Lagrangian multipliers relating to conditions (26) and (27), respectively. Condition (27) gives rise to the following complementary slackness condition:

$$
\mu(1-\beta)=0
$$

The first order conditions for the entrepreneur's problem are the following:

$$
\begin{aligned}
\Pi-\phi(I-Q)-\psi^{\prime}(e)-\lambda \psi^{\prime \prime}(e)+\lambda \frac{(I-Q)(1-\phi)-\beta A}{e^{2}} & =0 ; \\
\lambda A & =\mu e .
\end{aligned}
$$

Equations (26) and (29) together give us

$$
\begin{aligned}
\frac{1}{e}\{(I-Q)(1-\phi(1-e))-A\} & \\
+\frac{1}{e}(1-\beta) A= & \Pi-\psi^{\prime}(e) \\
= & \lambda\left[\psi^{\prime \prime}(e)-\frac{1}{e^{2}}\{(I-Q)(1-\phi)-\beta A\}\right] \\
& +\phi(I-Q) \\
= & \lambda\left[\psi^{\prime \prime}(e)-\frac{1}{e^{2}}\{(I-Q)(1-\phi)-A\}\right] \\
& +\phi(I-Q),
\end{aligned}
$$




\section{PUBLIC INITIATIVES TO SUPPORT ENTREPRENEURS}

where the last line follows from the preceding one by equations (28) and (30). Rearranging equation (31) gives us equation (32):

$$
(I-Q)(1-\phi)-A=\frac{\lambda e^{2} \psi^{\prime \prime}(e)-e(1-\beta) A}{\lambda+e} .
$$

Two cases are of interest, according to the sign of the left hand side of (32). For lemma 1, we need only consider the case where the left hand side of equation (32) is positive. This is the case precisely when $\phi<\hat{\phi}$, where $\hat{\phi}$ is given by equation (9). In this case, the right hand side of equation (32) must also be positive and, since $\beta \leq 1$, we must therefore have $\lambda>0$. Hence, by equation (30), $\mu>0$ so that, by the complementary slackness condition (28), $\beta=1$, as in part 1 of proposition (1). Then, using the binding participation constraint (7) with $\beta=1$, we obtain equation (10). Substituting $\beta=1$ into the incentive compatibility constraint (26) gives us equation (8), which is illustrated in figure 1. The existence of $\underline{\phi}$ follows immediately from this figure, using the argument in the paragraph immediately before proposition 1.

To find the sign of $e^{\prime}(\phi)$ when $\phi<\hat{\phi}$, we differentiate equation (8) with respect to $\phi$ to obtain the following:

$$
e^{\prime}(\phi)=\frac{(1-e)(I-Q)}{e \psi^{\prime \prime}(e)+\phi(I-Q)+\psi^{\prime}(e)-\Pi} .
$$

To determine the sign of $e^{\prime}(\phi)$, substitute $\beta=1$ into equation (32):

$$
\{(I-Q)(1-\phi)-A\}(\lambda+e)=\lambda e^{2} \psi^{\prime \prime}(e)
$$

When $\beta=1$, equation (26) can be re-written as follows:

$$
\left(\Pi-\psi^{\prime}(e)\right) e-\{(I-Q)(1-\phi)-A\}-e \phi(I-Q)=0
$$

Using equation (34) to substitute for $\{(I-Q)(1-\phi)-A\}$ in equation (35) gives us the following:

$$
\begin{aligned}
\lambda e\left\{e \psi^{\prime \prime}(e)-\Pi+\psi^{\prime}(e)+e \phi(I-Q)\right\} & =e^{2}\left(\Pi-\psi^{\prime}(e)-\phi(I-Q)\right) \\
& =e\{(I-Q)(1-\phi)-A\}
\end{aligned}
$$

The right hand side of this expression is equal $e$ times the left hand side of equation (32) which is positive by assumption. Hence so is the demoninator of equation (33), and thus $e^{\prime}(\phi)>0$, as in the lemma. 


\section{PUBLIC INITIATIVES TO SUPPORT ENTREPRENEURS}

\section{Proof of Proposition 1}

Part 1 of the proposition follows immediately from lemma 1. Part 2 corresponds to the case where $\underline{\phi} \leq \phi<\hat{\phi}$. This case was studied in the proof of lemma 1 , where we proved that $\beta=1$. Equation (10) is obtained by substituting this value for $\beta$ into the participation constraint (7) and, as demonstrated in the proof of lemma (1), effort is increasing in $\phi$ in this region.

Part 3 of the proposition corresponds to the case where the left hand side of equation (32) is non-positive, which happens precisely when

$$
\phi \geq \hat{\phi}
$$

If in this case we had $\lambda>0$ then we would also have $\mu>0$ and hence, by the complementary slackness condition (28), $\beta=1$, which would contradict the non-positivity of equation (32). Hence $\lambda=\mu=0$, and equation (32) reduces to equation (37).

$$
\beta=\frac{(I-Q)(1-\phi)}{A}
$$

Inserting this expression into the participation constraint (7) gives us

$$
R=I-Q
$$

Setting $\lambda=0$ into equation (29) gives us equation (13). Using the chain rule to differentiate this expression with respect to $\phi$ then gives us the following:

$$
e^{\prime}(\phi)=-\frac{I-Q}{\psi^{\prime \prime}(e)}<0
$$

which concludes the proof.

\section{Proof of Proposition 2}

For a given level $Q$ of co-funding, we know from section 2 that the optimal choice of subsidy is $\hat{\phi}(Q)$, defined in equation (9). If this level violates the budget constraint (14) then by proposition

1 , the optimal $\phi$ is the one that makes the budget constraint bind. Hence, for a given $Q$, the credit support agency will set $\phi=\phi^{*}(Q)$, where

$$
\phi^{*}(Q) \equiv \min \left\{\hat{\phi}(Q), \frac{B-Q(1+\rho)}{(1-e)(I-Q)}\right\} .
$$


Equation (40) may also be written as follows:

$$
\phi^{*}(Q)= \begin{cases}\frac{B-Q(1+\rho)}{(1-e)(I-Q)} & , \text { if } B<Q(e+\rho)+(1-e)(I-A) \\ \hat{\phi}(Q) & , \text { if } B \geq Q(e+\rho)+(1-e)(I-A) .\end{cases}
$$

The credit support agency's problem therefore reduces to the following:

$$
\max _{Q \geq 0} \mathscr{W}\left(Q, \phi^{*}(Q)\right)
$$

For a given $Q$ we consider the two cases that arise in equation (41).

First, suppose that $B<Q(e+\rho)+(1-e)(I-A)$, so that $\phi^{*}(Q)=\frac{B-Q(1+\rho)}{(1-e)(I-Q)}<\hat{\phi}$. In this case the analysis performed under case 1 of section (2) applies. We therefore have

$$
\begin{aligned}
\frac{d \mathscr{W}}{d Q} & =e^{\prime}(Q)\left(\Pi-\psi^{\prime}(e)\right) \\
& =\frac{e^{\prime}(Q)}{e}\left\{(I-Q)\left(1-\phi^{*}(Q)(1-e)\right)-A(1-e)\right\} \\
& =\frac{e^{\prime}(Q)}{e}\{I-B+Q \rho-A(1-e)\}
\end{aligned}
$$

where the second line follows from the incentive compatibility constraint (8). We know from equation (14) that $I-A-B>0$, so the curly bracketed term in equation (43) is positive. The functional form of $\phi^{*}$ allows us to express $Q$ in terms of $\phi$, so by the chain rule, $e^{\prime}(Q)=e^{\prime}(\phi) \phi^{\prime}(Q)$. We know from equation (33) that $e^{\prime}(\phi)>0$ and direct differentiation gives us

$$
\phi^{\prime}(Q)=\frac{-(1+\rho) I+B}{(1-e)(I-Q)^{2}} ;
$$

using equation (14) again, the numerator of this expression is less than $-A-\rho I<0$, so $\phi^{\prime}(Q)<0$ and hence

$$
\frac{d \mathscr{W}}{d Q}<0
$$

It follows immediately from equation (44) that, when $B<Q(e+\rho)+(1-e)(I-A)$, the credit support agency should set $Q=0$ and set $\phi=\phi^{*}(Q)$, as in part 1 of proposition (2).

The second case arises when $B \geq Q(e+\rho)+(1-e)(I-A)$, so that $\phi^{*}(Q)=\hat{\phi}(Q)$. Then

$$
\begin{aligned}
\frac{d \mathscr{W}}{d Q} & =e^{\prime}(Q)\left(\Pi-\psi^{\prime}(e)\right) \\
& =e^{\prime}(Q) \hat{\phi}(I-Q) \\
& =e^{\prime}(Q)(I-Q-A),
\end{aligned}
$$




\section{PUBLIC INITIATIVES TO SUPPORT ENTREPRENEURS}

where the second line follows from the incentive compatibility constraint (13). In this case, we know from equation (39) that $e^{\prime}(\phi)<0$, and straightforward differentiation gives us

$$
\phi^{\prime}(Q)=\hat{\phi}^{\prime}(Q)=-\frac{A}{(I-Q)^{2}}<0
$$

It follows that $\frac{d \mathscr{W}}{d Q}$ has the same sign as $(I-Q-A)$. Hence, when the credit support agency has sufficient funds to provide the optimal level $\hat{\phi}(Q)$ of guarantees at a given level of co-funding $Q<I-A$, it will increase welfare further by increasing the level of co-funding. Equation (45) indicates that, as it does so, it will reduce the guarantee that it offers. Since $\frac{d \mathscr{W}}{d Q}$ changes sign as soon as either $Q>I-A$ or as soon as the budget constraint binds, the credit support agency will stop increasing $Q$ as soon as either of these events occurs. Note that, when $Q$ attains its socially maximal level of $I-A, \hat{\phi}=0$.

\section{Proof of Proposition 4}

The entrepreneur selects $a$ and $b$ to maximize $V(a, b)$. The result is true provided $a$ is increasing in $V_{1}$ and $b$ is decreasing in $V_{1}$.

The entrepreneur's maximization problem yields the following first order conditions:

$$
\begin{aligned}
b\left(e^{F B} \Pi-\psi\left(e^{F B}\right)\right)+(1-b) X & =\frac{\partial c}{\partial a} \\
a\left(e^{F B} \Pi-\psi\left(e^{F B}\right)-X\right) & =\frac{\partial c}{\partial b},
\end{aligned}
$$

where we define $X \equiv V_{1}-Q$. We wish to prove that $\frac{\partial a}{\partial X}>0>\frac{\partial b}{\partial X}$.

Assume that $c(a, b)=c(a)+c(b)$. We have

$$
\begin{aligned}
& \frac{\partial a}{\partial X}=\frac{(1-b) \frac{\partial^{2} c}{\partial b^{2}}-a\left(V_{2}-X\right)}{\frac{\partial^{2} c}{\partial a^{2}} \frac{\partial^{2} c}{\partial b^{2}}-\left(V_{1}-X\right)^{2}} \\
& \frac{\partial b}{\partial X}=\frac{(1-b)\left(V_{2}-X\right)-a \frac{\partial^{2} c}{\partial a^{2}}}{\frac{\partial^{2} c}{\partial a^{2}} \frac{\partial^{2} c}{\partial b^{2}}-\left(V_{1}-X\right)^{2}} .
\end{aligned}
$$

For very convex $c$, the denominator in these two expressions is positive, the numerator in the first is positive, and in the second is negative. The result follows immediately. 